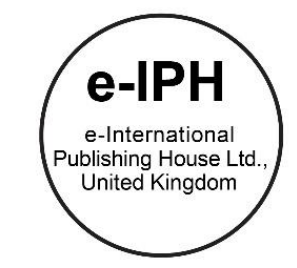

\title{
Attitude towards Sustainable Product among Malaysian Consumers
}

\author{
Muhammad Fauzan Abu Bakar, Clement anak Jimel \\ Faculty of Art and Design, \\ Universiti Teknologi MARA, Cawangan Sarawak, Jalan Meranek, 94300 Kota Samarahan, Sarawak, Malaysia. \\ mfauzan@uitm.edu.my, clementjimel@uitm.edu.my \\ Tel: +60133616460
}

\begin{abstract}
This research investigates consumers' attitude towards the acceptance of a sustainable product (SP). The current research on consumers' behaviour mainly focuses on "determinants" or "factors" affecting attitudes, while; this research offers a parallel shift, focusing on consumers' attitude influencing the acceptance of a sustainable product. Three main variables undergo in-depth examination: consumers' attitudes (CA), consumers' persuasion (CP) and consumers' ethics (CE). This study develops a model of sustainability, considering the strengths and limitations of existing models. The theoretical framework for this study is based on the theory of reasoned action (TRA), the theory of planned behaviour (TPB), the attribution theory (AT) and the Thompson \& Barton environmental attitudes model (EAM)
\end{abstract}

Keywords: Sustainable Product; Product Acceptance; Malaysian Consumers; Individual Attitudes, Persuasion and Ethical Belief

eISSN: 2398-42870 2020. The Authors. Published for AMER ABRA cE-Bs by e-International Publishing House, Ltd., UK. This is an open access article under the CC BYNC-ND license (http://creativecommons.org/licenses/by-nc-nd/4.0). Peer-review under responsibility of AMER (Association of Malaysian Environment-Behaviour Researchers), ABRA (Association of Behavioural Researchers on Asians) and CE-Bs (Centre for Environment-Behaviour Studies), Faculty of Architecture, Planning \& Surveying, Universiti Teknologi MARA, Malaysia.

DOI: https://doi.org/10.21834/ebpj.v5iSI3.2526

\subsection{Introduction}

Acceptance of new and unfamiliar product innovations tends to create self-cautiousness among consumers, resulting in different level of attitudinal expressions (Luo, Olechowski \& Magee, 2012; Luo, Warkentin \& Li, 2013). Understanding these differences will elucidate on the relevant factors in the acceptance of product innovation, and help differentiate those factors, for successful acceptance processes. Apart from the reported importance of sustainable product innovation, various studies also display that it can cause uncontrolled consumers' behaviour. These factors impact a heavy burden on the environment, resulting in environmental and societal problems (Cui, Jiao, Jiao, 2016; Guerra, Ribeiro, Fernandez, Bailey, Barbosa, \& Neiva, 2016; Huijts, Molin \& Steg, 2012; Irandoust, 2016; Martin-Pena, Diaz-Garrido\& Sanchez-Lopez, 2014). Developing sustainable product innovation is more than a goal for the future. It is a survival approach that will inform and ensure the long-term survival of humanity, as well as make qualitative improvements in consumers' daily lifestyles. Research proves that the acquisition of sustainable product will eventually reduce the possibility of environmental degradation, pollution and climate change (Guerra, Ribeiro, Fernandez, Bailey, Barbosa, \& Neiva, 2016; Irandoust, 2016; Moon, Bergey, Bove \& Robinson, 2016; Parrish, 2007). Brundtland (1987), as cited by Berardi (2013, p. 73), established that "sustainability is a form of development which meets the needs of the present without compromising the ability of future generations to meet their own needs". As such, consumers often find it difficult, with their lifestyle and their perspective, to accept new product innovation that contributes to sustainability (Gmelin \& Seuring, 2014). In today's world, the development and

eISSN: 2398-42870 2020. The Authors. Published for AMER ABRA CE-Bs by e-International Publishing House, Ltd., UK. This is an open access article under the CC BYNC-ND license (http://creativecommons.org/licenses/by-nc-nd/4.0). Peer-review under responsibility of AMER (Association of Malaysian Environment-Behaviour Researchers), ABRA (Association of Behavioural Researchers on Asians) and cE-Bs (Centre for Environment-Behaviour Studies), Faculty of Architecture, Planning \& Surveying, Universiti Teknologi MARA, Malaysia.

DOI: https://doi.org/10.21834/ebpj.v5iSI3.2526 
implementation of a sustainable product is not only an unavoidable social and environmental issue; it is also a significant challenge for many industries and individuals (Goepp, Zwolinski\&Caillaud, 2014). As mentioned by Chang, Moraes and Leek (2011), the question that needs answering is: can consumers contribute to sustainability? Their core ability and role in fostering societal change towards a more sustainable and environment-friendly mode of living is still being explored.

\subsection{Research Approach}

This research focuses on consumers' attitudes, persuasions and ethical belief, and their effects on their acceptance process of a sustainable product. The key issues surrounding sustainable product innovations have expanded, where moral values and consumers' concerns shift between greater or lesser inclination towards the environmental concern. To test CA, CP and CE, four main theories were executed and expand. The 'theory of reasoned action' (TRA) and the 'theory of planned behaviour' (TPB) are the theory that best explain attitudes. Attribution theory (AT) will further explain the persuasions, while Thompson and Barton's Environmental Attitudes Model (EAM) will explain consumers' ethical belief. All four theories are used and expanded to explain the current phenomenon of consumers' attitudes towards a sustainable product. Thus, it will allow the expansion of the theoretical model in product acceptance, filling in the gap in the existing theoretical framework. Therefore, this research can elucidate an consumers' perceptions from the possible outcomes of accepting sustainable product (Agamuthu \& Victor, 2011; Bachok, Ponrahono, Osman, Jaafar, Ibrahim, \& Mohamed, 2015; Bohnsack, Pinkse \& Kolk, 2014; Bourlakis, Maglaras, Aktas, Gallear, \& Fotopoulos, 2014; Carrigan, Moraes \& Leek, 2011; Chen \& Tung, 2014; Collins, 2011; Iveroth \& Bengtsson, 2014; Nagalingam, Kuik \& Amer, 2013; Quazi \&Talukder, 2010).

\subsection{Theoretical Framework}

This research will develop a model for sustainable product acceptance, with consideration of the existing models' strengths and limitations. The theoretical research framework for this research is based on TRA, developed by Fishbein and Ajzen (1980); TPB, developed by Ajzen (1991); AT, by Heider (1958); and Thompson and Barton's (1994) EAM. The model will include several modifications that these older models lack, as explained in the reviewed literature. The CA and CP elements are based on TRA, TPB and AT. The third category, CE is explained by Thompson and Barton's (1994) EAM.

The CA is derived from TRA, TPB and AT; they reflect that consumers' intention to accept a new product is influenced by their personality (CA) and surroundings (CP). AT describes the surrounding that affects consumers' decision as situational (CP), whereby the consumers' situation will act as the trigger for their intention to accept a sustainable product. Both CA and CP are essential in explaining the function of attitudes towards a sustainable products. It integrated into the research to acknowledge the consumers' opinions on the environmental issues that can influence its acceptance of a sustainable product.

The third category is CE, derived from Thompson and Barton's (1994) EAM. Other researchers who have utilized this model also identified CE as an element, as it explains how a consumer makes ethical decisions about the environment. It helps explain the consumers' perception of environmental values, which is why it is considered an essential inclusion for the research model. It will explain why consumers base their acceptance of a sustainable product on their ethical beliefs concerning the environment.

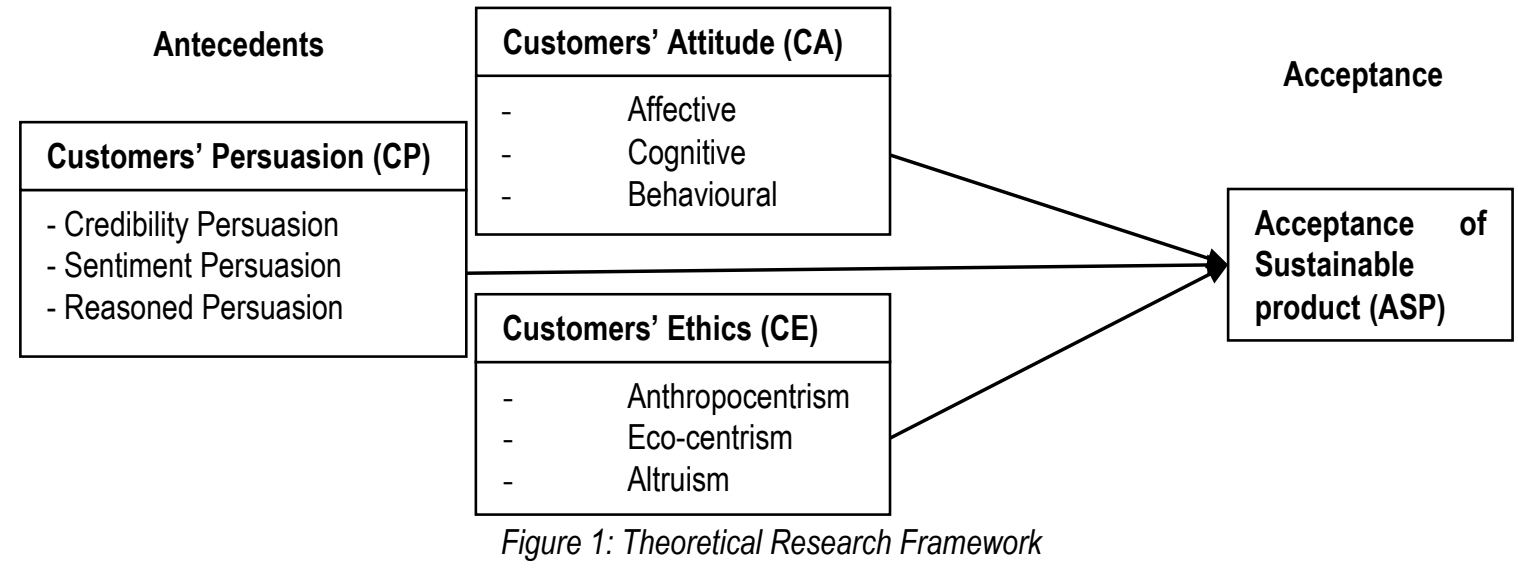

\subsection{Research Methodology}

This research is of an explanatory type: it collected information without changing the environment or manipulating the results. Many researchers have used multivariate analysis (e.g. Analysis of Variance, Regression or Factor Analysis) to find the relationship between selected variables (Sarstedt, Ringle, Smith, Reams \& Hair, 2014). This type of research can provide more information about naturally occurring human behaviours, attitudes and other characteristics. Explanatory research is usually the best methodology for information collection; demonstrates relationships and describes the world as it exists. According to Duguleana and Nicolae (2013), Explanatory is used when specific information on the relation between humans' attitudes and behaviours are needed. The instrument used is almost always a questionnaire. 
This research tested multiple hypotheses to evaluate the potential explanations for the observed relationships. It allowed for an explanation of the relationships between the variables. The hypotheses were based on the reviewed literature and developed with supporting examples. Based on the hypotheses, a quantitative survey for Malaysian consumers was constructed.

(H1) Affective CA has a significant relationship to the ASP.

(H2) Cognitive $C A$ has a significant relationship to the ASP.

(H3) Behavioural CA has a significant relationship to the ASP.

(H4) Credibility $C P$ has a significant relationship to the ASP.

(H5) Sentiment $C P$ has a significant relationship to the ASP.

(H6) Reasoned CP has a significant relationship to the ASP.

(H7) Anthropocentric CE has a significant relationship to the ASP.

(H8) Eco-centrism CE has a significant relationship to the ASP.

(H9) Altruism CE has a significant relationship to the ASP.

\subsection{Research Methods}

The study was conducted among consumers in Malaysia. The researcher has distributed the survey questionnaire randomly to 625 consumers in Malaysia, and the expected feedbacks are between 200 to 250 respondent. One of the main statistical tools that the research used during the analysis was the Partial Least Square Structural Equation Model (PLS-SEM). According to Hair, Sarstedt, Pieper \&Ringle (2012) and Hair, Hult, Ringle and Sarstedt (2013), the minimum sample size required for the analysis is ten times the maximum number of variables in the research model. The appropriate sample size was suggested to be a minimum of 15 subjects for each predictor (variables) for a thorough multivariate analysis suggested by Hair (1998).

This research analyzed the data using Partial Least Square - Structural Equation Model (PLS-SEM) developed by Herman Wold (1974, 1982). By using the PLS-SEM, it will also be able to analyze small sample sizes for this research. Furthermore, PLS-SEM can measure multiple construct variables at the same time, allowing the research to evaluate multiple theories within one model. This research use four theories that been expand and modified according to SP literature. Thus, using PLS-SEM is essential to gain an accurate measurement of the data collected (Hair, Hult, Ringle, \&Sarstedt, 2013; Hair, Sarstedt, Pieper \&Ringle, 2012; Sarstedt, Ringle, Smith \& Hair, 2014; Sarstedt, Ringle, Smith, Reams \& Hair, 2014). By using the PLS-SEM algorithm to run a path coefficient model analysis, this research can determine CA towards a sustainable product. The researcher evaluated the theoretical research framework and further determined the coefficient of determination. Furthermore, 'blindfolding' and 'predictive' relevance will be calculated to summarize the results.

\subsection{Data Analysis and Findings}

The data collected for this study derived from 242 respondents. A total of 234 sets of questionnaires were used, while three respondents opt-out in the middle of the participation, and the rest five survey questionnaires were disqualified as the respondents did not answer the questions appropriately.

\begin{tabular}{|c|c|c|c|}
\hline Variables & Composite Reliability & $\begin{array}{l}\text { Convergent Validity } \\
\text { (AVE) }\end{array}$ & Discriminant Validity \\
\hline Affective CA & .859 & .723 & Yes(0.907 > 0.425) \\
\hline Cognitive CA & .827 & .618 & Yes(0.847 > 0.663) \\
\hline Behavioural CA & .842 & .665 & Yes(0.875 > 0.743) \\
\hline Credibility CP & .851 & .695 & Yes(0.892 > 0.663) \\
\hline Sentiment CP & .841 & .660 & Yes(0.872 > 0.707) \\
\hline Reasoned CP & .839 & .656 & Yes $(0.870>0.646)$ \\
\hline Anthropocentrism CE & .844 & .673 & Yes $(0.879>0.595)$ \\
\hline Eco-centrism CE & .844 & .670 & Yes(0.878 > 0.733) \\
\hline Altruism CE & .844 & .671 & Yes $(0.878>0.514)$ \\
\hline Acceptance (ASP) (DV) & .828 & .622 & Yes $(0.850>0.501)$ \\
\hline
\end{tabular}




\subsection{Composite Reliability}

According to Nunally \& Bernstein (1994), composite reliability values from 0.60 to 0.70 are acceptable in exploratory research, while in more advanced research, values between 0.70 and 0.90 can be stated as satisfactory. As shown in 'table 1', it indicates that the composite reliability values of all the variables are considered as satisfactory.

\subsection{Convergent Validity}

To measure and establish convergent validity on the variables, the researcher gets it by their average variance extracted value (AVE). The AVE is equivalent to the communality of a construct. An AVE value of 0.50 or higher indicates that, on average, the construct explains more than half of the variance of the variables. Convergent validity assessment builds on the AVE values as the evaluation criterion. The AVE values of all the variable are well above the required minimum level of 0.50 . Thus, the independent and dependent variables of the theoretical research model have high levels of convergent validity.

\subsection{Discriminant Validity}

Discriminant validity is the extent to which a variable is truly distinct from other variables by empirical standards. This shows that a variable is unique, and it captures phenomena that are not presented by other variables in the theoretical research model. The FornellLarcker criterion is a conservative approach to assess discriminant validity. These methods will compare the square root of every AVE values with the latent variable correlations. Thus, the square root of each variable's AVE should be greater than its highest correlation with any other variables. As shown in 'Table 1', the square root of all variables is greater than the highest values of other correlation, which indicates that all variables are discriminant valid.

\subsection{Summary of Findings}

By running the PLS-SEM analysis, estimates are obtained for the structural model relationships, which represent the hypothesized relationships among the variables. The path coefficients have standardized values between -1 and +1 . As indicated in 'Table 2', the path coefficient that shows a significant and positive value is 'Affective' CA (0365) and 'Altruism' CE (0.295). The path coefficient value that is closer to 0 , that can be explained as non-significant are 'Cognitive' CA (-0.016), 'Behavioural' CA (0.089), 'Credibility' CP (0.060), 'Sentiment' CP (0.034), 'Reasoned' CP (-0.105), 'Anthropocentrism' CE (0.020), and 'Eco-centrism' CE (-0.058).

Although the path coefficient can estimate the significant values of a variable, ultimately it depends on its standard error that is obtained by employing bootstrapping. In bootstrapping, subsamples are randomly drawn from the original set of data. Each subsample is then used to estimate the model. This process is repeated until a large number of random subsamples have been created. In this research, the total of subsamples is 20,000 to represent Consumers in Malaysia. The bootstrapping will be applied to compute the $t$ value. The empirical $t$ value needs to be larger than the critical value, to determine whether the coefficient is significant at a certain error probability. After computing the $t$ values, any value that is more than 1.65 (significant level $=10 \%$ ) will be considered as significant. As indicated in 'Table 2', the $t$ value of each path coefficients is presented. The results show both significant and nonsignificant. The PLS path shows that the relationship between affective attitude towards acceptance is very significant at $t$ value of 7.445 (>1.65). Both 'Cognitive' CA and 'Behavioural' CA variables showed a non-significant relationship towards acceptance of SP, where the $t$ value is $0.223(<1.65)$, and $1.223(<1.65)$. Even the CP variables show a non-significant relationship towards the ASP as the $t$ value for 'Credibility' SP is $0.708(<1.65)$, while 'Sentiment' CP has a t value of $0.369(<1.65)$, and 'Reasoned' CP is 1.171 $(<1.65)$. In terms of CE, only 'Altruism' CE has a strong significant value towards the ASP at $t$ value of $3.450(>1.65)$, while 'Anthropocentrism' CE and 'Eco-centrism' CE have a non-significant relationship at $t$ values of $0.233(<1.65)$, and $0.692(<1.65)$.

Other than computing the $t$ value, this research will also report the $p$ values that correspond to the probability of erroneously rejecting the null hypothesis. To determine the $p$ values as a significance value, the value needs to be described as significant when $p<0.001, p<0.05$, and $p<0.10$. Anything that is higher than 0.10 is considered as non-significant. The variables that show significance values $(p<0.001)$ is 'Affective' $C A$ and 'Altruism' CE.

Table 2: Significance Testing Results of PLS-SEM Algorithm

\begin{tabular}{|c|c|c|c|c|c|}
\hline & $\begin{array}{r}\text { Path } \\
\text { Coefficients }\end{array}$ & t Values & $\begin{array}{r}\text { Sig. } \\
\text { Levels }\end{array}$ & p Values & $90 \%$ Confidence Intervals \\
\hline Cognitive $\rightarrow$ Acceptance & -.014 & .223 & NS & .824 & {$[-0.142,0.140]$} \\
\hline Credibility $\rightarrow$ Acceptance & .060 & .708 & NS & .479 & {$[-0.095,0.220]$} \\
\hline Sentiment $\rightarrow$ Acceptance & .034 & .369 & NS & .712 & {$[-0.146,0.203]$} \\
\hline Reasoned $\rightarrow$ Acceptance & -.106 & 1.171 & NS & .241 & {$[-0.274,0.076]$} \\
\hline Eco-centrism $\rightarrow$ Acceptance & -.062 & .692 & NS & .489 & {$[-0.232,0.100]$} \\
\hline Altruism $\rightarrow$ Acceptance & .295 & 3.450 & $* * *$ & .001 & {$[0.124,0.462]$} \\
\hline
\end{tabular}

The most commonly used measure to evaluate the structural model is the coefficient of determination. The coefficient of determination ( $R^{2}$ value) ranged from 0 to 1 , with higher levels indicating higher levels of predictive accuracy. In the research of consumers' attitudes, $R^{2}$ value of 0.20 and above are considered as high predictive accuracy. In this research, $R^{2}$ value of $0.26,0.13$, or 0.02 for a dependent variable can be described as substantial, moderate, or weak (Cohen, 1988; Hair, Ringle \& Sarstedt, 2011; 
Henseler, Ringle \& Sinkovics 2009; Wong, Soh, \& Chong, 2016). The coefficient of determination ( $R^{2}$ value) for acceptance shows a substantial value of 0.262 . The change in the $R^{2}$ value when a specified independent variable is omitted from the model can be used to evaluate whether the variables have substantive impact on the dependent variables. This measure is referred to as the $f^{2}$ effect size. Assessing the $f^{2}$ are that values of $0.02,0.15$, and 0.35 , respectively, represent small, medium, and large effects of the independent variables (Cohen 1988). Indicated in 'Table 3 ', the $f^{2}$ effect size for all the relationship between independent and dependent variables are listed. The relationships that have weak effect size are 'Cognitive' CA $\rightarrow$ ASP (0.000), 'Behavioural' CA $\rightarrow$ $\operatorname{ASP}(0.003)$, 'Credibility' $\mathrm{CP} \rightarrow \mathrm{ASP}(0.002)$, 'Sentiment' $\mathrm{CP} \rightarrow \mathrm{ASP}(0.001)$, 'Reasoned' CP $\rightarrow$ ASP (0.004), 'Anthropocentrism' CE $\rightarrow$ ASP (0.000), and 'Eco-centrism' CE $\rightarrow$ ASP (0.002). The relationship that has a small $f^{2}$ effect size is 'Altruism' CE $\rightarrow$ ASP $(0.054)$, and there is only one relationship that considered having medium $f^{2}$ effect size, which is 'Affective' CA $\rightarrow$ ASP $(0.130)$.

In addition to evaluating the magnitude of the $R^{2}$ values as a criterion of predictive accuracy, this study will also determine the $Q^{2}$ value. This measure is an indicator of the theoretical research model's predictive relevance. It will accurately predict the data points of the construct measurements of each independent and dependent variables. The $Q^{2}$ value for acceptance variable carries the value of 0.169, which indicates that the dependable variable has predictive relevance (Hair, Hult, Ringle, \&Sarstedt, 2013; Wong, Soh, Chong, 2016). Similar to the $f^{2}$ effect size approach for assessing $R^{2}$ values, the relative impact of predictive relevance can be compared by means of the measure to the $q^{2}$ effect size. As indicated in 'Table 3 ', the $q^{2}$ effect size that is considered as weak are 'Cognitive' CA $\rightarrow$ ASP (-0.001), 'Behavioural' CA $\rightarrow$ ASP (0.001), 'Credibility' CP $\rightarrow$ ASP (-0.001), 'Sentiment' CP $\rightarrow$ ASP (-0.001), 'Reasoned' CP $\rightarrow$ ASP (0.001), 'Anthropocentrism' CE $\rightarrow$ ASP (0.000), and 'Eco-centrism' CE $\rightarrow$ ASP (0.001). The small $q^{2}$ effect sizes that are shown in the table are 'Affective' CA $\rightarrow$ ASP (0.089), 'Altruism' CE $\rightarrow$ ASP (0.031).

Table 3: Summary of Results

\begin{tabular}{|l|r|r|r|}
\hline & Path Coefficients & $\boldsymbol{f}^{2}$ Effect Size & $\boldsymbol{q}^{2}$ Effect Size \\
\hline Affective $\rightarrow$ Acceptance & .365 & .130 & .089 \\
\hline Cognitive $\rightarrow$ Acceptance & -.014 & .000 & -.001 \\
\hline Behavioural $\rightarrow$ Acceptance & .089 & .003 & .001 \\
\hline Credibility $\rightarrow$ Acceptance & .060 & .002 & -.001 \\
\hline Sentiment $\rightarrow$ Acceptance & .034 & .001 & -.001 \\
\hline Reasoned $\rightarrow$ Acceptance & -.106 & .004 & .001 \\
\hline Anthropocentrism $\rightarrow$ Acceptance & .020 & .000 & .000 \\
\hline Eco-centrism $\rightarrow$ Acceptance & -.062 & .002 & .001 \\
\hline Altruism $\rightarrow$ Acceptance & .295 & .054 & .031 \\
\hline
\end{tabular}

\subsection{Discussion and Implication}

The results from the PLS-SEM path analysis, in general, show that affective attitudes and altruistic belief to be positive and significant towards the acceptance of a sustainable product (Figure 2). This showed that if consumers have stronger positive feelings towards sustainable products, there will be more possibilities for them to accept a sustainable product. Furthermore, the research showed that Malaysian consumers have high 'Altruistic' values, which put others well-being before their own. The more their actions affect the people around them, the more they will eventually lead them to change their daily intake towards a sustainable product. As shown in 'Table 3', the variable that has contributed the most to explain the acceptance is the 'Affective' CA with predictive accuracy ( $f^{2}$ effect size) value of 0.130 and predictive relevance ( $q^{2}$ effect size) of 0.089 . This show that 'Affective' CA is the main antecedents for consumers to accept a sustainable product, which support our first hypothesis (H1). As Buijs \& Lawrence (2013) stated, these emotional state can drove individuals' towards making a decision to approach a sustainable product with a feeling of attachment, respect, responsibility, and joy towards sustainability. 'Affective' CA involve directly within individuals' action towards a particular phenomenon. Their emotional state will create reactions when encountering a problem or an opportunity, thus lead to action of a particular phenomenon. Thus, shows that with high 'Affective' CA, individuals that deciding for themselves and their family, can lead towards accepting sustainable product. According to Jepson, Brannstrom \& Persons (2012), consumers tend to take a new opportunity as long as it can create and help them to gain more benefits in improving their daily lifestyle. In term of SP, the opposite effects occur where the well-being of the people around them have been put as the priority. The results of this research agree with Verdugo, Bonnes, Fonllem, Sing, Armenta \& Carrus (2009) and Hirsh (2014), where 'Altruistic' CE of selflessness can always open to change, which have an impact among consumers that care for others. This data has shown supportive results on the hypothesis (H9). The usages of dangerous material and resources that will affect other individuals' health and safety have lead consumers to change their daily intake towards a sustainable product.

Antecedents

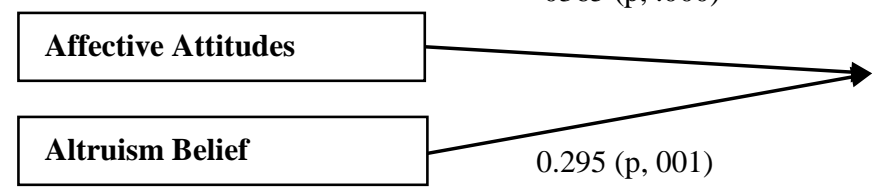

Acceptance

Acceptance of
$\begin{aligned} & \text { Sustainable } \\ & \text { product }\end{aligned}$

Figure 2: PLS-SEM Path Theoretical Research Model 


\subsection{Conclusion}

By identifying a comprehensive list of CA, CP and CE antecedents, and perception towards the ASP, this study departs from the traditional sustainable study that only applies a few factors. By employing quantitative data, this study offers an understanding of the different factors that play a role in affecting consumers' ASP. The PLS-SEM path analysis indicated that nine independent variables accounted for $72.2 \%$ of the variance in the consumers' ASP.

The data from the PLS-SEM path analysis indicated that 'Affective' CA and 'Altruism' CE have high coefficient and predictive ability towards the ASP. Thus, it suggested that the agency, government or NGOs which aim to implement sustainability among consumers need to focus on creating a surrounding environment based on these two approaches. This is important, where a different approach may prove to be futile for the consumers. To implement and manage sustainability that can enhance consumers' capabilities, the government and NGOs must recognize the CA, CP and CE that influence consumers' ASP. The findings of this study will help the government to identify factors and provide favourable environment conditions prior to implementation of SP. It also contributes to a better understanding of the antecedents that promote ASP.

\section{References}

Agamuthu, P. and Victor, D. (2011). Policy trends of extended producer responsibility in Malaysia. Waste Management \& Research, 29 (9), 945-953.

Bachok, S., Ponrahono, Z., Osman, M., Jaafar, S., Ibrahim, M. and Mohamed, M. (2015). A preliminary study of sustainable transport indicator in Malaysia: The case study of Klang Valley public transportation. Journal of Environmental Sciences, 28, 464-473.

Berardi, U. (2013). Clarifying the new interpretation of concept of sustainable building. Journal of Sustainable Cities and Society, 8, 72-78.

Bohnsack, R., Pinkse, J. and Kolk, A. (2014). Business models for sustainable technologies: Exploring business model evolution in the case of electric vehicles. Journal of Research Policy, 43 (2), 284-300.

Bourlakis, M., Maglaras, G., Aktas, E., Gallear, D. and Fotopoulos, C. (2014). Firm size and sustainable performance in food supply chains: insights from Greek Consumers. International Journal of Production Economics, 152, 112-130.

Carrigan, M., Moraes, C. and Leek, S. (2011). Fostering responsible communities: a community social marketing approach to sustainable living. Journal of Business Ethics, 100 (3), 515-534

Chang, Y., Chang, H., Chi, H., Chen, M. and Deng, L. (2012). How do established firms improve radical innovation performance? The consumers' capabilities view. Journal of Technovation, 32 (7-8), 441-451.

Chen, M. and Tung, P. (2014). Developing an extended theory of planned behavior model to predict consumers' intention to visit green hotels. International Journal of Hospitality Management, 36, 221-230.

Cohen, J. (1988). Statistical power analysis for the behavioral sciences. Mahwah, NJ.LawranceErlbraum.

Dardak, R. and Adham, K. (2014). Transfering agricultural technology from government research institution to private firms in Malaysia. Procedia of Social and Behavioral Sciences, 115, 346-360.

Duguleana, L. and Nicolae, C. (2013). Quantitative marketing research on behavior of the small and medium companies on financial advisory services. Bulletin of the Transylvania University of Brasov, 6 (55), 25-30.

Gmelin, H. and Seuring, S. (2014). Determinants of sustainable new product development. Journal of Cleaner Production, 69, 1-9.

Goepp, V., Zwolinski, P. and Caillaud, E. (2014). Design process and data models to support the design of sustainable remanufactured products. Journal of Computers in Industry, 65 (3),480-490.

Hair, J., Anderson, R., Tatham, R., and Black, W. (1998). Multivariate Data Analysis. Upper Saddle River, New Jersey: Prentice Hall.

Hair, J., Hult, G., Ringle, C. and Sarstedt, M. (2011). PLS-SEM: Indeed a silver bullet. Journal of Marketing Theory and Practice, 19, 139-151).

Hair, J., Hult, G., Ringle, C. and Sarstedt, M. (2013). A Primer on Partial Least Squares Structural Equation. Newbury Park, CA: Modelling Sage Publications.

Hair, J., Sarstedt, M., Pieper, T and Ringle, C. (2012). The use of partial least squares structural equation modeling in strategic management research: A review of past practices and recommendations for future applications. Long Range Planning, 45 (5-6), 320-340.

Henseler, J., Ringle, C. and Sinkovics R. (2009). The use of partial least squares path modeling in international marketing. Advances in International Marketing, 20 , 277-320.

Hirsh, J. (2014). Environmental sustainability and national personality. Journal of Environmental Psychology, 38, 233-240.

Huijts, N., Molin, E. and Steg, L. (2012). Psychological factors influencing sustainable energy technology acceptance: a review-based comprehensive framework. Renewable and Sustainable Energy Review, 16 (1), 525-531.

Iveroth, E. and Bengtsson, F. (2014). Changing behavior towards sustainable practices using information technology. Journal of Environmental Management, 139, 5968.

Jepson, W., Brannstrom, C. and Persons, N. (2012). "We don't take the pledge": Environmental skepticism at the epicenter of US wind energy development. Journal of Geoforum, $43(4), 851-863$. 
Luo, J., Olechowski, A. and Magee, C. (2012). Technology-based design and sustainable economic growth. Journal of Technovation, 34 (11), $663-677$.

Luo, X., Warkentin, M. and Li, H. (2013). Understanding technology acceptance trade-off: a conjoint analysis approach. Journal of Computer Information Systems,53 (3), 65-74.

Malaysia, (2011). Profile of small and medium enterprise. Economic Census 2011, Department of Statistic, Malaysia.

Martin-Pena, M., Diaz-Garrido, E. and Sanchez-Lopez, J. (2014). Analysis of benefits and difficulties associated with firms' environmental management systems: the case of the Spanish automotive industry. Journal of Cleaner Production, 70, 220-230.

Nagalingam, S., Kuik, S. and Amer, Y. (2013). Performance measurement of product returns with recovery for sustainable manufacturing. Journal of Robotic and Computer-Integrated Manufacturing, 29 (6), 473-483.

Nunally, J. and Bernstein, I. (1994), Psychometric theory. New York: McGraw-Hill.

Oliveira, T. and Martins, M. (2011). Literature review of information technology acceptance model at firm level. The Electronic Journal Information Systems Evaluation,14 (1), 110-121.

Parrish, B. (2007). Designing the sustainable enterprise. Journal of Futures, 39 (7), 846-860.

Quazi, A. and Talukder, M. (2010). Demographic determinants of acceptance of technological innovation. Journal of Computer Information Systems, 52 (1), $34-47$.

Sarstedt, M., Ringle, C., Smith, D. and Hair, J. (2014). PLS-SEM: looking back and moving forward. Long Range Planning, 47 (3), $132-137$.

Sarstedt, M., Ringle, C., Smith, D., Reams, R and Hair, J. (2014). Partial least square structural equation modeling (PLS-SEM): a useful tool for family business researchers. Journal of Family Business Strategy, 5 (1), 105-115.

Tarute, A. and Gatautis, R. (2013). ICT impact on Consumers performance. Procedia of Social and Behavioral Sciences,110, 1218-1225.

Verdugo, V., Bonnes, M., Fonllem, C., Sing, B., Armenta, M. and Carrus, G. (2009). Correlates of pro-sustainability orientation: the affinity towards diversity. Journal of Environmental Psychology, 29 (1), 34-43.

Wong, W., Soh, K. and Chong, C. (2016). Differentiated service consumption and low cost production: Striking a balance for a sustainable competitive advantage in Malaysia. International Journal of Production Economics. 